\title{
A IGREJA UNIVERSAL DO REINO DE DEUS: UM ATOR E AS SUAS COSTURAS DA SOCIEDADE BRASILEIRA CONTEMPORÂNEA.
}

Pablo Semán Professor da Universidade de San Martin, Argentina.

Importantes e cheias de consequências são as descobertas deste trabalho de Oro. Nesta intervenção, e devido ao meu próprio percurso de pesquisa, quero fazer referência específica a algumas delas: as que no texto de Oro atingem o pentecostalismo e, mais especificamente ainda, aquelas referentes à Igreja Universal do Reino de Deus. Dita igreja, nascida há menos de três décadas, tornou-se massiva e, quase que surpreendentemente, se politiza de forma tão ágil quanto relevante. Esses fenômenos nos deixam inquietos e nos fazem perguntar: como pensar a atuação desta igreja em relação à sociedade brasileira contemporânea?. O que esse fenômeno revela desta sociedade e quais são os termos que permitem capturar melhor essa realidade?. Não pretendo dar uma resposta exaustiva a questões tão amplas e estratégicas mas, seguindo os passos dados pelo artigo de Oro, quero sugerir uma hipótese que deveria guiar esforços mais prolongados e que liga os dados da nossa especialização no campo religioso com interpretações mais abrangentes da sociedade brasileira. Baseado na interpretação de Sorj (2000) do caráter multifacetado da sociedade brasileira (especialmente a coexistência do estado racionalizador, do capitalismo e dos padrões sócio-culturais que fazem da brasileira uma sociedade religiosa), concluirei que a Igreja Universal é um tipo de instituição especial: ela deve ser concebida como um ator, como um princípio composição que costura algumas dessas múltiplas facetas transformando a sociedade.

Começarei insistindo com uma questão: as descobertas do texto que estamos discutindo. E quero assinalar entre elas, duas sobre as quais trabalharei de perto nos dois primeiros pontos desta comunicação para, 
num terceiro momento, desenvolver um argumento na direção da hipótese antecipada. Brevemente, e de forma condensada, podemos apresentar essas duas contribuições que baseiam o meu argumento. Como primeira contribuição, o texto nos mostra realidades novas e incontrastáveis num campo onde a produção bibliográfica tinha misturado as realidades empíricas com especulações, tão necessárias quanto distorsivas (uma vez que era ainda insuficiente a manifestação dos fenômenos, e que a novidade do pentecostalismo não era muito agradável para uma ciência social que tinha e tem compromissos laicos ou com as vertentes emancipadoras do catolicismo e do protestantismo). Assim, onde presumia-se que o pentecostalismo ia ser simplesmente despolitizante, se mostra que a IURD gera uma confissão politizada. Onde era previsto que o pentecostalismo da IURD só poderia agir em concordância com a direita temos o espantoso apoio ao PT. O que em outro artigo era colocado como hipótese (Oro \& Semán, 1997), que o pentecostalismo se politiza situacional e não essencialmente, agora é comprovado de forma tal que se pode dizer que esta descoberta muda o cenário das discussões em torno das relações entre pentecostalismo e política. A segunda contribuição que eu gostaria de destacar será o que farei referência como a demonstração da contingencialidade da relação entre expressões religiosas e políticas e que permite pensar a especificidade do trabalho histórico que tanto do lado da religião como da política organizam a especificidade das suas relações no Brasil contemporâneo.

\section{I - A religião entramada na política}

A primeira questão que nos trás o trabalho é que a religião, isto é, as instituições, os agentes e as ideologias religiosas (e não uma longínqua e inespecífica função consagratória que pode ser agenciada por qualquer instituição), é uma presença generalizada nos partidos políticos locais. Os da ordem e os de mudança, os antigos e os modernos, sempre, em algum grau, e ainda que seja instrumentalmente, admitem, toleram, incentivam a presença do elemento religioso e dos agentes da 
religião nas suas mensagens e na sua oferta eleitoral.

Danièle Hervieu-Léger cobra das pesquisas e pesquisadores da religião análises que levem em conta a "fluidité du croire des sociétés modernes, et sur les processus multiples de redistribution des significations qui lient intrinsequement l'un à l'autre l'ordre du religieux et celui du politique" (Hervieu-Léger, 1996:8). Isto é o que o trabalho de Oro concretiza de forma indiscutível. No contexto destes achados, e no final de meu argumento principal, quero acrescentar duas reflexões sobre esta presença da religião na política. De uma parte a) a relativa ao lado religioso, a disposição das organizações religiosas em se envolver politicamente e, de outro, b) relativa a política, a atitude dos partidos políticos que, por mais interesse que possam ter na obtenção de votos, não podem incluir a presença religiosa a não ser superando algumas circunstâncias específicas que historicamente geraram certa distância da religião.

a) $\mathrm{O}$ envolvimento político das organizações religiosas descrito por Oro mostra que se tem consumado um desenvolvimento sobre o que quero agregar à primeira observação complementar. Pode-se tratar de que as organizações religiosas, presumivelmente detentoras de um grande caudal eleitoral, se politizem corporativamente na busca de vantagens e interlocuções privilegiadas com o Estado; pode-se tratar de que os partidos políticos, de forma interesseira, permitam estas aparições e as mobilizem malgrado os desejos dessas organizações religiosas ou apesar de seus próprios desejos (às vezes laicos, às vezes vagamente religiosos mas prudente com as identificações denominacionais). Mas, o que de qualquer forma deve-se sublinhar como um processo maior, subjacente e que possibilita essa politização, é a nacionalização do pentecostalismo, a sua incorporação ao mapa local e a sua interiorização deste mapa. Isto que parece natural não é o resultado de um processo de longa duração que foi assinalado pioneiramente por autores advindos do mundo evangélico. Padilla (1991) observava que o pentecostalismo demonizava a política e abstinha-se de participar na mesma e que essa atitude era decorrente do caráter missionário e estrangeiro da origem dessas religiões mais do que uma característica estruturalmente apolítica do pentecos- 
talismo. Hoje, estamos observando um momento histórico (do qual o trabalho de Oro é uma precisa e incontrastável demonstração) que precisa desta premissa para sua correta interpretação: os pentecostalismos, desenvolvidos em um contexto onde a separação das denominações e o Estado era um fato consumado, implantados na América Latina por líderes estrangeiros desvinculados da política das sociedades onde chegavam, dificilmente iriam se politizar. Mas, isso não deixaria de acontecer uma vez que seus líderes fossem locais e estivessem entranhados nos sentimentos e formas de conflitos locais aos quais a massa de fiéis também pertencia. Umas poucas gerações, e é isto o que estaria acontecendo, desmentindo com fatos a profecia da suposta posição alienada (no sentido que muitas vezes adquire o termo: socialmente descomprometido) que corresponderia naturalmente aos pentecostais. Ainda deve-se dizer que a nacionalização dos pentecostais se faz mais plenamente compreensível e tangível quando se percebe que o fenômeno da politização é correlativo a outro movimento de enraizamento cultural nacional que, na longa duração, resulta quase simultâneo: a politização do pentecostalismo é contemporânea (e em boa parte concomitante) ao desenvolvimento das expressões brasileiras do pentecostalismo (a IURD, que é um paradigma desses desenvolvimentos, não é apenas formada e fundada por brasileiros. É também a Igreja pentecostal que mais recebe no seu ritual a influência da cultura religiosa brasileira como já assinalou Oro (1997) ao afirmar a umbandização da IURD).

b) Por outro lado, devemos observar que os motivos da politização dos pentecostais pareceriam gerais e até sem importância. Porém, não o são: ética e justiça substancial, distributiva, social, não são qualquer motivo. Eles decorrem desse fenômeno de localização nacional com o acréscimo do seu enraizamento sócio-cultural. Mas, esta afirmação se faz compreensível com a antecipação da segunda reflexão: a da boa acolhida que a política dá à religião. Verdadeiramente, deve chamar a atenção o fato dos políticos procurarem estes apoios e pensarem que lhes trás um suplemento de legitimação, o que, às vezes, acontece efetivamente. Isto diz respeito, como um sintoma, de uma situação histórica relativamente nova. Historicamente tinha-se afirmado que o sistema de 
partidos do Brasil era fragmentado e inconsistente. Atualmente, tem-se insinuado que os eleitorados, cada vez mais, resultam constantes, coerentes, e nacionalmente articulados criando a possibilidade de expressões políticas mais estruturadas e abrangentes que ainda devem aparecer e que exigem certas mutações nas regras que organizam a vida dos partidos políticos. A aparição dos candidatos religiosos como tais, a sua recepção nos diversos partidos políticos, mostra que a estrutura de motivações desses eleitorados estaria mudando. Com efeito: a dita nacionalização dos eleitorados, que se acelerou com o processo de recuperação democrática, não tinha rejeitado a religião mas tinha deixado a mesma à distância. Nem a participação de certas correntes da igreja católica no processo de formação e desenvolvimento do PT contradizem esta afirmação na medida em que sou solidário das interpretações que mostram que esse movimento é, de alguma forma, secularizante.

Vejamos: se essa aproximação dos partidos às igrejas e às religiões é uma novidade, quais são as razões? Por que este acréscimo de religião aos motivos eleitorais dos partidos?. Por que a aceitação de um matiz religioso, muitas vezes confessional? A resposta, apesar de ser quase óbvia, deve ser explicitada pois sempre se corre o risco de descontextualizar a politização das igrejas. A transição democrática no Brasil, como na Argentina e no Uruguai, foi paralela a um processo de questionamento e transformação de uma ordem econômica e social que sinteticamente poderia ser chamada de "welfare latino americano". Este processo, muitas vezes a simples incorporação de graus diversos mas sempre fortes dos princípios neoliberais, implicou um desgaste enorme das representações políticas tradicionais que assumiram e geriram esses processos póspopulistas. Os setores mais prejudicados por essas políticas não por acaso constituíram-se em uma possível base de mobilização político-religiosa: as reformas neoliberais afetaram negativamente os mais pobres, que são justamente os setores cujo universo simbólico fornece mais espaço a descrições cosmológicas e éticas do universo sócio-político. Para esses setores que percebem o mundo em relações entre parte e todo, em termos de trocas cuja justiça pode ser avaliada ou denunciada, as reformas neoliberais significaram justamente a quebra de um pacto. E isto é o que 
os grupos religiosos que se politizam denunciam (uma quebra de um modelo ético, que equivale ao mesmo tempo a uma falha ética, a uma presença cosmologicamente negativa) e pedem reparação. Para eles, o mal-estar e o sofrimento pessoal, mas também social, não são questões da presença negativa do "imperialismo" ou da "necessidade de dinamizar a economia com investimentos" que pregam os mais liberais, ou da falta de desenvolvimento da cidadania, mas sim do desajuste de uma ordem, de um fato que cria, em uma sensibilidade específica, uma irritação e uma possibilidade de mobilização político-religiosa.

\section{II - Contingência e trabalho histórico na relação entre Religião e Política}

Entretanto, estas pontes, esta reconfiguração das fronteiras entre a religião e a política e do mesmo caráter destas esferas, não são efeito de uma necessidade histórica: não surgem nem por simples desgaste da política nem por um deslocamento automático da confiança das lideranças político-terrenas às celestiais. Esta reconexão é o efeito de um trabalho histórico do lado da política e do lado da religião. Antes de enfocar e analisar este último aspecto é preciso reter uma premissa que emerge dessa análise: o fato desta reconexão depender de um trabalho histórico específico permite caracterizar a relação entre religião e política além da simples contestação da secularização. Nem a secularização nem a reaparição das práticas do sagrado no âmbito da política são roteiros que atualizam uma situação pré-traçada. Como sugere Velho (1995), trata-se de um jogo contingente em que as narrativas do sagrado (como as do político) procuram o seu lugar, e o ganham ou não, em diálogo com sensibilidades e institucionalidades existentes, com os limites, mas também as possibilidades, que ditas institucionalidades e sensibilidades oferecem a esse trabalho. Esta contingência do social, esta não necessidade da presença ou a ausência da religião, exige uma compreensão de processos históricos singulares, das condições de sua possível presença.

E não é qualquer mecanismo que está presente na aproximação 
entre as esferas da religião e da política. Não é necessariamente, como mostra o artigo de Oro, a repetição do sobre-estimado apelo mediático, o fator da instalação do religioso na política. Ele também não tem sucesso pela sua origem exclusivamente: não é, necessariamente, o fato de fazer um apelo ao que é diretamente identificado como religioso que fará com que os eleitores que pertencem a uma congregação religiosa votem no candidato proposto pela mesma. O trabalho de Oro nos mostra com clareza exemplar que os capitais acumulados no campo religioso não se convertem imediatamente em políticos e que, no caso brasileiro, parece haver capitais religiosos que, mais facilmente do que outros, podem se trocar em políticos. Fiéis não são diretamente votantes, o alto carisma religioso do candidato não o faz, na mesma proporção, politicamente atrativo. É possível apreciar a contracara positiva destes fatos com dois pontos colocados por Oro que assinalam os caminhos pelos quais o trabalho da religião permite enraizá-la na política; ou seja, a ênfase na ética e nos problemas sociais (e a ajuda aos mais pobres), e um certo tipo de organização, favorecem a capitalização política da religião.

Assim, parece que o trabalho que permite a religião se entranhar positivamente com a política abrange, no mínimo, duas dimensões: a ideológica e a organizacional. No ponto anterior temos dito algo da primeira dessas dimensões. A intervenção da religião se articula em torno de motivos que, em geral e só em geral, não teriam nada de novo em relação aos programas dos partidos que as igrejas apoiam ou nos quais inscrevem candidatos: ética e justiça social. Não sabemos se esse programa tem mais crédito entre o eleitorado na voz de agentes religiosos que fazem parte de chapas eleitorais, mas sim sabemos que eles pensam que sua presença nelas se justifica por esses motivos mais do que por quaisquer outros. Neste sentido, é central uma colocação de Oro: a ideologia dos agentes político-religiosos em relação à política é que sua pessoa, pela sua relação com o divino, é a antítese da corrupção e da insensibilidade perante os fracos, que o seu pertencimento ao mundo do sagrado é pertinente e eficaz pois representa uma moralidade diferente. Se o grande fenômeno político religioso da teologia da libertação articulava o cristianismo em termos de categorias sócio-políticas, e só assim ele 
projetava um programa de mobilização política, os agentes religiosos que se tornaram políticos traduzem sua relação com o mundo espiritual em termos morais e cosmológicos que os fariam mais éticos e mais capazes de agir contra o que, na sua lógica, fundaria a pobreza ética e a insensibilidade social da política: o demônio. Sabendo o quanto esta crença é pré-existente, sabendo o quanto ela é acionável, pode-se dizer que, com ou sem plano consciente, os candidatos religiosos ganham o seu lugar na política fazendo vibrar essa corda que, viva no eleitorado, estava adormecida na mentalidade dos políticos secularizados. A santa política contra os demônios da insensibilidade e da corrupção é o aríete com que os agentes religiosos galvanizam a mentalidade cosmológica que temos citado mais acima e a mobilizam politicamente. Se, como afirmamos no primeiro ponto, tínhamos uma sociedade na qual os motivos religiosos podiam ser ativados como matriz de leitura das experiências de perda devidas ao processo sócio-econômico, encontramos na pregação da santa política a forma de concretizar as suas possibilidades de mobilização, uma forma de reconectar a religião com a política. A santa política é a forma de tornar ato as potências da base de mobilização político-religiosa que mencionamos mais acima.

Mas, para que isto aconteça deve-se levar em conta a segunda dimensão: a organizacional. Não qualquer candidatura política advinda do mundo religioso obtém sucesso. A possibilidade de ser eleito depende, não só dos motivos ideológicos, mas também do tipo de organização da igreja a qual pertence o candidato e do tipo de representação que este exerce. $\mathrm{O}$ fato demonstrado por Oro é que candidatos oficiais de igrejas com grande capacidade de mobilização são os que têm mais probabilidades de triunfo eleitoral. Quais são essas igrejas: as que possuem um alto grau de interiorização dos princípios de organização burocrática e empresarial. Peter Fry anunciava pioneiramente a proximidade do pentecostalismo e o mundo burocrático, e Oro, em trabalhos anteriores, caracterizava o neopentecostalismo pelo seu caráter empresarial. Com este dado podemos avançar esta conclusão: o sucesso do pentecostalismo e, especialmente da IURD, na política moderna (eleitoral, massiva, mediada pela TV, a imprensa e a rádio), estava, de alguma forma, pré- 
contido nas características próprias desta igreja. Sendo afim com o mundo da organização burocrática ela era mais do que idônea na prática da mobilização política a grande escala.

\section{III - Um ator que costura as múltiplas facetas do Brasil Contemporâneo.}

Assim, parece que a IURD mistura elementos aparentemente opostos mas constitutivos da sociedade brasileira: a presença dos efeitos do Estado racionalizador, do capitalismo e, ao mesmo tempo, de padrões culturais diversificados que fazem da sociedade brasileira uma sociedade religiosa (Sorj, 2000). A pergunta que temos formulado inicialmente pode, então, ser assim reformulada: como pensar a ação política da IURD numa sociedade multifacetada e tensionada pelos seus múltiplos traços?

Duas indicações de Alain Touraine ajudam a captar os sentidos mais gerais de como a IURD atua na sociedade brasileira. A primeira delas se refere ao caráter multitemporal das sociedades latino americanas, a presença combinada e conflitiva dos elementos próprios da modernidade, das suas tendências à crise mas, também, do que não foi plenamente incorporado a ela. A segunda dessas indicações refere à afirmação do sujeito como princípio do social. Esta concepção não é igual à postulação da hiperpotência do indivíduo e sim a um giro copernicano no interior do universo de pensamento que atende à máxima de explicar o social pelo social. Enquanto a declinação tradicional deste preceito privilegia o sistema, a versão de Touraine privilegia o ator, aquele que intervém de maneira tal que a produção do social seja sempre mais que reprodução, alteração. $\mathrm{O}$ ator, seja este um indivíduo ou um grupo, não é uma entidade fora da sociedade mas o princípio de produção da sociabilidade, o contraponto conceitual do que na sociologia clássica acaba sendo reificado como uma realidade metasocial, o social fora da história.

Articulando estas premissas com o que temos dito acima sobre a forma como a Universal captura, ao mesmo tempo, dois princípios igualmente constitutivos da sociedade brasileira, é possível sugerir uma 
hipótese: a IURD é um ator que opera como uma dobradiça dos diversos momentos constitutivos da sociedade brasileira. Ao mesmo tempo que se apóia nos mecanismos de sua face moderna, presentifica o rosto cosmológico que a compõe. Nesse movimento que o legitima e o torna operativo na totalidade social, redefine essa mesma totalidade e resignifica a política. As bases da identificação política tinham sido os lugares sociais do trabalhador, as ideologias, as relações pessoais. Agora podem ser, também, as identidades religiosas. O movimento, que não deve surpreender, é análogo ao que a Universal já tinha feito com o dinheiro: antes a moeda, o equivalente geral de todas as mercadorias, tinha sido traduzida por esta igreja na lógica da oferta e do sacrifício; hoje é o voto, a relação que nem sempre foi de cidadania, é inscrito numa lógica cosmológica na perspectiva da guerra santa. Assim, enquanto ator, como princípio de transformação do existente, a IURD é um catalizador da composição entre aspectos da sociedade brasileira que muitas vezes permanecem reciprocamente alheios.

\section{Referências bibliográficas}

HERVIEU-LÉGER, Danièle (1996). “Croire en modernité: au-delà de la problématique des champs religieux et politique" In: Religion et Democratie. Paris, Fayard.

ORO, Ari, (1997). "Neopentecostrais e Afrobrasileiros: quem vencerá esta guerra?”. In: DEBATES do NER. Ano 1, N. 1, pp. 10-39.

ORO, Ari Pedro \& SEMÁN, Pablo. “Os Pentecostalismos nos países do Cone-Sul: panorama e estudos”. In: Religião e Sociedade. V. 18, N. 2, 1997:127-150.

PADILLA, Rene (1991). "Los evangélicos, nuevos actores en el escenario político latinoamericano", In: PADILLA, Rene. De la marginación al compromiso: los evangélicos y la política en America Latina. Ecuador, Fraternidad Teológica Latinoamericana. 
SORJ, Bernardo, (2000). A Nova Sociedade Brasileira. Jorge Zahar Editor, Rio de Janeiro.

VELHO, Otávio (1995). "Religião e modernidade: roteiro para uma discussão.” In: VELHO, Otávio. Besta Fera: recriação do mundo. Rio de Janeiro, Relume Dumará. pp.207-219. 